\title{
Hepatitis C Virus-Associated Acalculous Cholecystitis and Review of the Literature
}

\author{
William F. Wright, DO, MPH; Kathryn Palisoc, DO; Casey N. Pinto, PhD, CRNP; \\ James A. Lease, DO; and Salim Baghli, MD, MPH
}

\begin{abstract}
Acute acalculous cholecystitis (AAC) is an infrequently encountered clinical condition associated with high morbidity and mortality. Viral infection associated AAC is rare, but it is most commonly associated with Epstein-Barr virus, cytomegalovirus, dengue virus, hepatitis $A$, hepatitis $B$, human immunodeficiency virus, disseminated visceral varicella-zoster virus infection, Zika virus, and hepatitis $C$. We report on a patient who was first diagnosed with a chronic hepatic $C$ infection and subsequently with acalculous cholecystitis.
\end{abstract}

Keywords: Hepatitis C virus; Acalculous cholecystitis; Viral cholecystitis

A cute acalculous cholecystitis (AAC) is a relatively infrequent condition characterized as acute gallbladder inflammation without demonstration of biliary sludge or cholelithiasis. ${ }^{1-5}$ Histologically, the common feature of this condition primarily involves blood vessel injury within the muscularis and serosa layers of the gallbladder. ${ }^{1,2}$ The most common presentation is among patients who are critically ill from burns, sepsis, or trauma. ${ }^{3-5}$ Mortality rates range from $10 \%-50 \%$ due to the severity of underlying illness as well as the increased risk of gallbladder gangrene or perforation. ${ }^{4,5}$ Viral infections associated with AAC most commonly are associated with Epstein-Barr virus (EBV); however, other viral pathogens include cytomegalovirus (CMV), dengue virus, hepatitis A (HAV), hepatitis B (HBV), human immunodeficiency virus (HIV), disseminated visceral varicella-zoster virus (VZV) infection, and Zika virus. ${ }^{6-13}$ Infection with hepatitis $\mathrm{C}$ virus $(\mathrm{HCV})$ has recently been reported in association with AAC. ${ }^{14-16}$ The purpose of this communication is to report a case of $\mathrm{HCV}$ associated acalculous cholecystitis.

\section{Case Report}

A male, aged 33 years, from Pennsylvania presented with 3-days onset of "flu-like symptoms" with generalized muscle

Corresponding Author: William F. Wright, DO, MPH, Division of Infectious Diseases, Department of Medicine, University of Pittsburgh Medical Center, Pinnacle, III South Front Street, Harrisburg, Pennsylvania I7I0I, Tel: (7I7) 755-I244 Fax: (717) 757-7644 aches, arthralgias, headaches, and fatigue as well as a 1-day onset of persistent nausea, vomiting, and epigastric abdominal discomfort. Medical history included nonspecific gastritis by esophagogastroduodenoscopy (EGD) 6-years prior and treatment naïve chronic HCV genotype 1a infection diagnosed 2 -years prior. While the patient had a prior history of intravenous opiate abuse, he tested negative on routine urinary toxicology screening over 2-years since his diagnosis of HCV. Abdominal computed tomography (CT) scan and right upper quadrant hepatic ultrasound (RUQ-US) examinations for elevated liver enzymes 3-years prior were unremarkable except for nonspecific periportal edema. Serum HCV-ribonucleic acid (RNA) level 2-years prior was 824,572 $\mathrm{IU} / \mathrm{mL}$ (5.92 LogIU/mL) [ref: undetected] and 1,420,000 IU/ $\mathrm{mL}(6.15 \mathrm{Log} \mathrm{IU} / \mathrm{mL})$ 1-month prior. The patient had no history of domestic or international travel.

Physical examination revealed maximum temperature of $36.6^{\circ} \mathrm{C}$, epigastric tenderness, no scleral jaundice, and no rash. Laboratory results showed serum neutrophilic leukocytosis of 14.7 cells $/ \mu \mathrm{L}$ (ref: $3.9-9.5$ cells $/ \mu \mathrm{L}$ ), creatinine of $2.69 \mathrm{mg} / \mathrm{dL}$ (ref: $0.40-1.20 \mathrm{mg} / \mathrm{dL}$ ), aspartate aminotransferase $144 \mathrm{U} / \mathrm{L}$ [ref: 11-35 U/L], alanine aminotransferase $102 \mathrm{U} / \mathrm{L}$ (ref: 10-60 U/L), alkaline

Received: March 22, 2019

Revised: June 30, 2019

Accepted: July I, 2019

doi: $10.312 \mid / \mathrm{cmr} .2019 .1499$ 
Table 1: Case Report summary of HCV associated acute acalculous cholecystitis cases published in the peerreviewed medical literature

\begin{tabular}{|c|c|c|c|c|c|c|}
\hline Reference & Age/Sex & $\begin{array}{l}\text { Diagnosis/ } \\
\text { Gallbladder } \\
\text { wall } \\
\text { thickness } \\
(\mathrm{mm})\end{array}$ & Comorbidity & $\begin{array}{l}\text { HCV viral } \\
\text { load (IU/ } \\
\text { mL) }\end{array}$ & Treatment & Outcome \\
\hline $2005^{14}$ & NR & NR & $\begin{array}{l}\text { Cryoglobulinemic } \\
\text { vasculitis }\end{array}$ & NR & $\begin{array}{l}\text { Percutaneous } \\
\text { cholecystectomy }\end{array}$ & Survived \\
\hline $2010^{15}$ & 35/Male & AAC/ 15.0 & Alcoholism & $1,000,050$ & Non-surgical & Survived \\
\hline $2016^{16}$ & 40/Female & AAC/ 20.0 & Dep, IVDU & 113,225 & Non-surgical & Survived \\
\hline Our case & 33/Male & AAC/ 15.2 & IVDU & $1,080,000$ & $\begin{array}{l}\text { Percutaneous } \\
\text { cholecystectomy }\end{array}$ & Survived \\
\hline
\end{tabular}

NR: not reported

Abbreviations: AAC, acute acalculous cholecystitis; Dep, depression; IVDU, intravenous drug use

phosphatase $132 \mathrm{U} / \mathrm{L}$ (ref: $30-110 \mathrm{U} / \mathrm{L}$ ), total bilirubin $1.0 \mathrm{mg}$ / dL (ref: $<1.1 \mathrm{mg} / \mathrm{dL}$ ), albumin $4.1 \mathrm{~g} / \mathrm{dL}$ (ref: $3.4-4.6 \mathrm{~g} / \mathrm{dL}$ ), and total protein $6.8 \mathrm{~g} / \mathrm{dL}$ (ref: $5.8-7.6 \mathrm{~g} / \mathrm{dL}$ ). Abdominal CT demonstrated possible underlying cholelithiasis or sludge (not pictured). RUQ-US demonstrated pericholecystic fluid and gallbladder wall thickening of $15.2 \mathrm{~mm}$ (Figure 1). Single anterior-posterior chest imaging demonstrated no acute pulmonary-alveolar disease (not pictured).

The patient demonstrated clinical decline after he was admitted, requiring initiation of mechanical ventilation for airway protection as well as vasopressors for hemodynamic support. Empirical antimicrobial therapy with vancomycin (15 $\mathrm{mg} / \mathrm{kg}$ intravenous every 12 hours), aztreonam (2 grams intravenous every 8 hours), metronidazole ( $500 \mathrm{mg}$ intravenous every 8 hours), and acyclovir ( $10 \mathrm{mg} / \mathrm{kg}$ intravenous every 8 hours) was initiated. Due to concerns for possible meningitis, cerebral spinal fluid (CSF) analysis revealed no pleocytosis with normal protein at $32 \mathrm{mg} / \mathrm{dL}$ (ref: $15-45 \mathrm{mg} / \mathrm{dL}$ ) and mild elevated glucose at $73 \mathrm{mg} / \mathrm{dL}$ (ref. $40-70 \mathrm{mg} / \mathrm{dL}$ ). CSF Gram stain showed no leukocytes, no red blood cells, and no microorganisms.

On hospital day 5, blood and CSF cultures remained negative for bacterial growth. The patient underwent laparoscopic cholecystectomy, with intraoperative findings of a significantly dilated gallbladder with edema. Gross pathology examination revealed a $11.5 \mathrm{~cm} \times 4.5 \mathrm{~cm} \times 2.5 \mathrm{~cm}$ specimen with a smooth shiny serosal surface, copious bile without sludge, and no calculi. Histologic examination demonstrated muscular wall thickness of $0.2 \mathrm{~cm}$, stromal edema, chronic inflammation with segmented neutrophils and lymphocytes, but no CMV cytoplasmic viral inclusions (Figure 2). Serum molecular testing for HCV RNA was $1,080,000 \mathrm{IU} / \mathrm{mL}(6.03 \log \mathrm{IU} / \mathrm{mL})$, CMV deoxyribonucleic acid (DNA) was $<200 \mathrm{IU} / \mathrm{mL}(<2.3$ $\log \mathrm{IU} / \mathrm{mL}$ ), EBV DNA was $<200$ copies $/ \mathrm{mL}$, and HIV-1 RNA was $<20$ copies $/ \mathrm{mL}$. The patient demonstrated immunity to $\mathrm{HBV}$ with a surface antibody titer of $354 \mathrm{mIU} / \mathrm{mL}$ (ref: $>10$ $\mathrm{mIU} / \mathrm{mL}$ ), and serologic testing for HAV was non-reactive.
Testing for VZV was not performed due to lack of clinical findings to support disseminated visceral disease. Additionally, testing for Dengue and Zika viruses were not performed due to lack of epidemiologic risk factors. Empirical treatment was discontinued upon subsequent negative cultures and serology testing. Clinical symptoms resolved, and he was discharged for planned outpatient initiation of HCV treatment.

\section{Discussion}

While viral hepatic infections are an unusual etiology for acute calculous cholecystitis (ACC), most cases have been related to $\mathrm{EBV}, \mathrm{HAV}$, and HBV. ${ }^{6,710} \mathrm{HCV}$ is a member of the Flaviviridae family and is characterized by a single positive-strand RNA genome that can be divided into seven genotypes. ${ }^{16}$ Acquisition of HCV most often results in chronic infection and inflammation leading to serious liver damage such as cirrhosis and hepatocellular carcinoma. ${ }^{16} \mathrm{HCV}$-induced AAC, such as seen

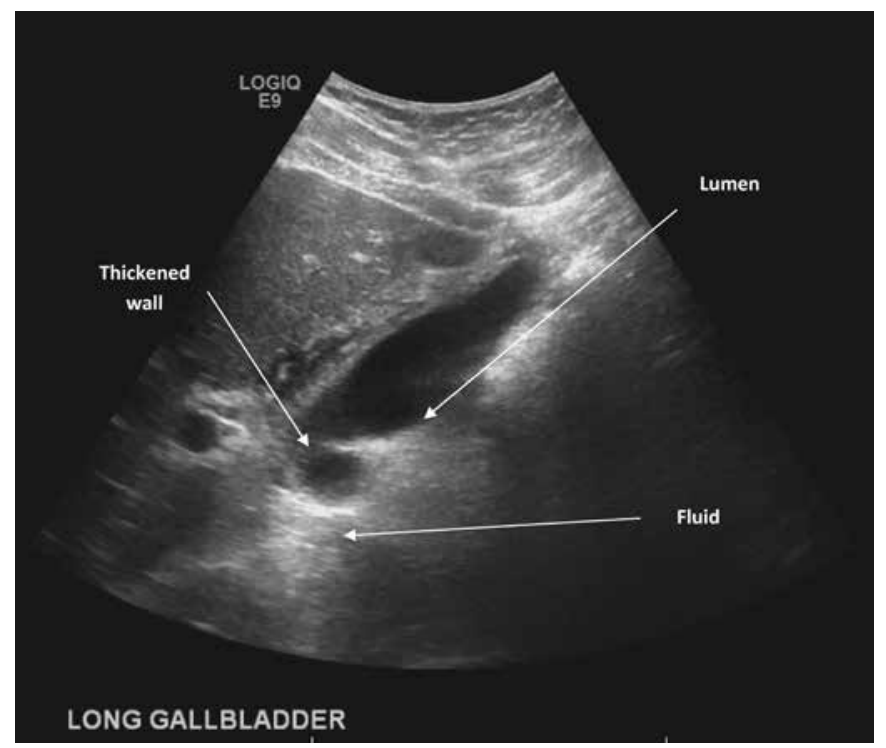

Figure 1. Transabdominal ultrasound scan (longitudinal view) demonstrating significant gallbladder wall thickening measuring up to $15.2 \mathrm{~mm}$ and pericholecystic fluid with no luminal calculi. 


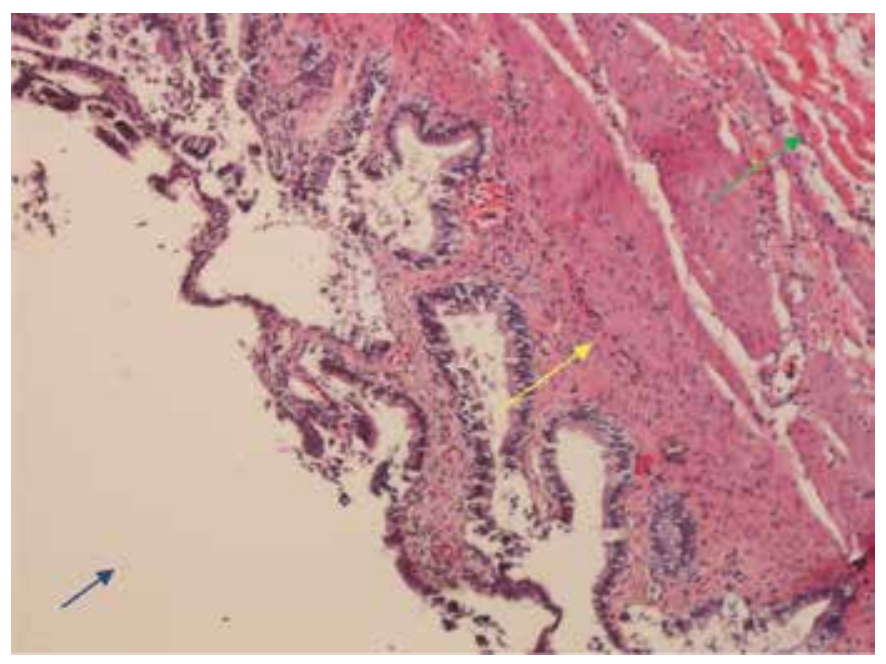

Figure 2. Gallbladder mucosa demonstrating marked inflammation with segmented neutrophils and lymphocytes (Yellow arrow) with stromal edema (Green arrow). Gallbladder lumen

in our patient, was unknown; therefore, a review of the published literature was performed by conducting a PubMed search that yielded three case reports (Table 1). ${ }^{14-16}$

Meier and colleagues ${ }^{14}$ reported a patient with chronic $\mathrm{HCV}$ infection presenting to the emergency department with abdominal pain, fever, and abdominal ultrasound findings of acute acalculous cholecystitis. Their patient underwent laparoscopic cholecystectomy with histologic findings consistent with cryoglobulinemic vasculitis. Plasmapheresis and immunosuppressive therapy also resulted in clinical resolution of illness in this patient. Trésallet and colleagues ${ }^{15}$ described the case of a 35-year-old patient presenting to the emergency department for the acute onset of mucocutaneous jaundice and $15.0 \mathrm{~mm}$ gallbladder wall thickening in the absence of biliary calculi. Serology for HAV, HBV, HIV, and CMV were reported negative, but HCV RNA levels were reported at $6.17 \log \mathrm{IU} / \mathrm{mL}$. Their patient had spontaneous resolution of clinical symptoms, and ACC resolved with conservative management. Omar and colleagues ${ }^{16}$ reported the case of a female, aged 40 years, with a previous history of $\mathrm{HCV}$ infection presenting to the emergency department with progressive upper abdominal pain, jaundice, nausea, and vomiting of 1-week duration. Abdominal ultrasound examination revealed diffuse gallbladder wall thickening up to $20.0 \mathrm{~mm}$ without cholelithiasis. While the authors did not report results of additional virologic testing, HCV RNA levels were $113,225 \mathrm{IU} / \mathrm{mL}(5.06 \log \mathrm{IU} / \mathrm{mL})$ of genotype 1a. Their patient had spontaneous resolution with conservative therapy, similar to the case reported by Trésallet and colleagues. Our patient met the diagnostic criterion for acute cholecystitis as described by the Tokyo international guidelines ${ }^{17}$ By axiomatic deduction, our case represents HCV-induced acalculous cholecystitis similar to previous published cases. ${ }^{14}{ }^{16} \mathrm{We}$ also propose that our patient may have had a prior $\mathrm{HCV}$-induced acalculous cholecystitis flare 3-years prior, when abdominal imaging had reported nonspecific periportal edema in the setting of elevated hepatic enzymes.
Whereas ACC is considered a local gallbladder disease process, AAC is typically a manifestation of systemic critical illness. ${ }^{1-6,19}$ A recent prospective study by Laurila and colleagues ${ }^{19}$ analyzing 84 gallbladder tissue samples among patients with AAC reported biliary infiltration into the mucosa and muscular layers, leukocyte arterial margination with nonthrombotic hypoperfusion (ischemia), focal lymphatic dilatation with interstitial edema, and less epithelial degeneration (necrosis) when histologically compared to ACC samples. A microangiography study by Hakala and colleagues ${ }^{20}$ among 15 gallbladder samples also reported that nonthrombotic small arterial occlusion was a consistent feature of AAC when compared to ACC. In a 10-year retrospective review, McChesney and colleagues ${ }^{21}$ proposed the pathogenesis of AAC is a progression from visceral arterial hypoperfusion (ischemia) to gallbladder wall inflammation, resulting in biliary stasis and bacterial invasion.

While the pathophysiology of viral-induced AAC is unknown, authors have proposed that a high concentration of viral antigens, particularly HAV and HBV, are localized in the gallbladder and biliary duct epithelial cells, resulting in immune-complex deposition and development of acute inflammation and ischemic injury. ${ }^{6}{ }^{6-16}$ Chronic $\mathrm{HCV}$ infection may also result in increased circulating immune-complexes, which may contribute to blood vessel injury within the muscularis and serosa layers of the gallbladder. ${ }^{1,2,14}$ Gallbladder and proximal biliary epithelial cells are susceptible to direct HCV infection with toll-like receptor-4 (TLR4) expression, correlating with the stage of hepatic inflammation. ${ }^{22,23}$ Therefore, it is further postulated that ongoing uncontrolled viral replication (eg, persistently elevated HCV RNA levels) may result in increased portal/septal myofibroblasts activity and inflammation, resulting in AAC. ${ }^{23}$ Although genotype 1a infection was also reported in one other case, ${ }^{16}$ it is unclear if other genotypes may induce AAC.

\section{Conclusion}

To the best of our knowledge, this report describes the fourth patient within the published medical literature with HCVrelated acalculous cholecystitis. Our case report and the other published cases ${ }^{14-16}$ suggest that HCV should be considered in the differential diagnosis of virus-induced AAC. Conservative management without antimicrobial therapy should be considered over surgical intervention. Standard recommendations for the treatment of $\mathrm{HCV}$ may result in decreased flares of HCV-related AAC. ${ }^{16,17}$ Clinicians should be aware of this complication. Finally, more cases are needed to develop optimal management strategies.

\section{References}

1. Glenn F. Acute acalculous cholecystitis. Ann Surg. 1979;189(4):458-465.

2. Glenn F, Becker CG. Acute acalculous cholecystitis. An increasing entity. Ann Surg. 1982;195(2):131-136. 
3. Shapiro MJ, Luchtefeld WB, Kurzweil S, Kaminski DL, Durham RM, Mazuski JE. Acute acalculous cholecystitis in the critically ill. Am Surg. 1994;60(5):335-339.

4. Barie PS, Fischer E. Acute acalculous cholecystitis. J Am Coll Surg. 1995;180(2):232-244.

5. Kalliafas S, Ziegler DW, Flancbaum L, Choban PS. Acute acalculous cholecystitis: incidence, risk factors, diagnosis, and outcome. Am Surg. 1998;64(5):471-475.

6. Bura M, Michalak M, Chojnicki M, Kowala-Piaskowska A, Mozer-Lisewska I. Viral Hepatitis A in 108 Adult Patients During an Eight-Year Observation in a Single Center in Poland. Adv Clin Exp Med. 2015;24(5):829836.

7. Unal H, Korkmaz M, Kirbas I, Selcuk H, Yilmaz U. Acute acalculous cholecystitis associated with acute hepatitis $B$ virus infection. Int $\mathrm{J}$ Infect Dis. 2009;13(5):e310-e312.

8. Kavin H, Jonas RB, Chowdhury L, Kabins S. Acalculous cholecystitis and cytomegalovirus infection in the acquired immunodeficiency syndrome. Ann Intern Med. 1986;104(1):53-54.

9. Keshavjee SH, Magee LA, Mullen BJ, Baron DL, Brunton JL, Gallinger S. Acalculous cholecystitis associated with cytomegalovirus and sclerosing cholangitis in a patient with acquired immunodeficiency syndrome. Can J Surg. 1993;36(4):321-325.

10. Agergaard J, Larsen CS. Acute acalculous cholecystitis in a patient with primary Epstein-Barr virus infection: a case report and literature review. Int J Infect Dis. 2015;35:67-72.

11. Bhatty S, Shaikh NA, Fatima M, Sumbhuani AK. Acute acalculous cholecystitis in dengue fever. J Pak Med Assoc. 2009;59(8):519-521.

12. Ono SK, Bassit L, Van Vaisberg V, et al. Acute acalculous cholecystitis during zika virus infection in an immunocompromised patient. Hepatology. 2018;67(5):2051-2054.

13. Braude MR, Trubiano JA, Heriot A, et al. Disseminated visceral varicella zoster virus presenting with the constellation of colonic pseudo-obstruction, acalculous cholecystitis and syndrome of inappropriate ADH secretion. Intern Med J. 2016;46(2):238-239.

14. Meier M, Hollulrich K, Perras B. A rare manifestation of cryoglobulinemic vasculitis: acalculous cholecystitis. Clin Gastroenterol Hepatol. 2005;3(10):A26.

15. Trésallet C, Bastien L, Rabahi Y, Cadi M, Leroux G, Menegaux F. [Hepatitis $\mathrm{C}$ virus infection revealed by an acute acalculous cholecystitis]. J Radiol. 2010;91(78):813-815.

16. Omar A, Osman M, Bonnet G, Ghamri N. Acute acalculous cholecystitis caused by Hepatitis C: A rare case report. Int J Surg Case Rep. 2016;19:78-81.
17. AASLD-IDSA HCV Guidance Panel. Hepatitis C Guidance 2018 Update: AASLD-IDSA

Recommendations for Testing, Managing, and Treating Hepatitis C Virus Infection. Clin Infect Dis. 2018;67(10):1477-1492.

18. Yokoe M, Hata J, Takada T, et al. Tokyo Guidelines 2018: diagnostic criteria and severity grading of acute cholecystitis (with videos). J Hepatobiliary Pancreat Sci. 2018;25(1):41-54.

19. Laurila JJ, Ala-Kokko TI, Laurila PA, et al. Histopathology of acute acalculous cholecystitis in critically ill patients. Histopathology. 2005;47(5):485492.

20. Hakala T, Nuutinen PJ, Ruokonen ET, Alhava E. Microangiopathy in acute acalculous cholecystitis. Br J Surg. 1997;84(9):1249-1252.

21. McChesney JA, Northup PG, Bickston SJ. Acute acalculous cholecystitis associated with systemic sepsis and visceral arterial hypoperfusion: a case series and review of pathophysiology. Dig Dis Sci. 2003;48(10):1960-1967.

22. Loriot MA, Bronowicki JP, Lagorce D, et al. Permissiveness of human biliary epithelial cells to infection by hepatitis $\mathrm{C}$ virus. Hepatology. 1999;29(5):1587-1595.

23. Vespasiani-Gentilucci U, Carotti S, Onetti-Muda A, et al. Toll-like receptor-4 expression by hepatic progenitor cells and biliary epithelial cells in HCV-related chronic liver disease. Mod Pathol. 2012;25(4):576-589.

\section{Author Affiliations}

William F. Wright, DO, MPH*; Kathryn Palisoc, DO†; Casey N. Pinto, PhD, CRNPł; James A. Lease, DO§; and Salim Baghli, MD, MPH†

*Division of Infectious Diseases, Department of Medicine, University of Pittsburgh Medical Center - Pinnacle, Harrisburg, Pennsylvania $\dagger$ Division of Hospital Medicine, Department of Medicine, University of Pittsburgh Medical Center - Memorial, York, Pennsylvania

†Division of Infectious Diseases, Department of Medicine, University of Pittsburgh Medical Center - Pinnacle, Harrisburg, Pennsylvania; and Department of Public Health Sciences, The Pennsylvania State University, University Park, Pennsylvania $\S$ Department of Pathology and Laboratory Medicine, University of Pittsburgh Medical Center-Memorial, York, Pennsylvania 